\title{
Desafios do clima para os povos indígenas: vulnerabilidade socioecológica na região do Submédio da Bacia Hidrográfica do rio São Francisco/Brasil
}

\author{
Climate challenges for indigenous peoples: socioecological vulnerability \\ in the Sub-Basin region of the São Francisco River Basin / Brazil
}

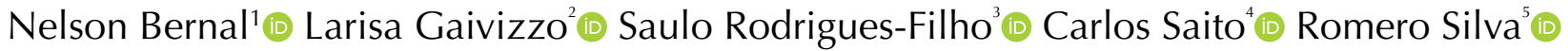 \\ Adriane Michels ${ }^{6}$ (i) Ana Claudia Almeida ${ }^{7}$ (i)
}

Para citar este artículo: N. Bernal Dávalos, L. Gaivizzo, S. Rodrigues Filho, C. Saito, R. Silva, A. Michels, A. Claudia Almeida "Desafios do clima para os povos indígenas: vulnerabilidade socioecológica na região do Submédio da Bacia Hidrográfica do rio São Francisco/Brasil". Revista Vínculos, vol. 17, n. 1, pp. 42-59, enero-junio. 2020. DOI: https://doi.org/10.14483/2322939X.15600

Recibido: 26-11-2019 / Aprobado: 19-03-2020.

\section{Resumo}

Estão previstas para as próximas décadas, por conta das mudanças climáticas e a desertificação, reduções significativas na produção de alimentos em diversas regiões do mundo. O grupo que irã sofrer maiores impactos prevê-se que serão as populações mais pobres, especialmente aquelas que moram em comunidades estabelecidas em pequenas parcelas de terra e são dependentes das condiçõe climáticas. Este artigo mostra como o fator fundiário, a estiagem, a renda e o incremento da populacional indígena, colocam os povos indígenas Tuxá e Pankararu numa situação de vulnerabilidade. Mostra-se que o aumento da população indígena e os eventos extremos provocados pelas mudanças climáticas podem comprometer o futuro do cultivo das principais culturas agrícolas desses povos, entre estes do feijão, arroz, mandioca e o milho, diminuindo a possibilidade de garantir sua alimentação, união e reprodução social. A população indígena do Brasil vem mostrando um interessante aumento, no entanto paralelamente a este fato, as áreas de plantio vêm se reduzindo, o que obriga aos tomadores de decisões diminuir as problemáticas

1 Sociólogo / Doutorando em Desenvolvimento Sustentável CDS, Universidade de Brasília UNB, Brasil. Aluno de doutorado e pesquisador da Rede Clima, Centro de Desenvolvimento Sustentável da UnB. Correio eletrônico: edruck_25@hotmail.com, Orcid: https://orcid. org/0000-0001-6778-555X

2 Agrônoma / Doutora em Ciência do Solo, Universidade Federal do Rio Grande do Sul, Brasil. Pesquisadora, Centro de Desenvolvimento Sustentável da UnB. Correio eletrônico: larisabech@gmail.com. Orcid. https://orcid.org/0000-0003-0084-1347

3 Geólogo / Doctor en Ciencias Naturales - Universidad Heidelberg, Alemania / Pós-Doc. en Estudios Ambientales, University of California, Santa Cruz e University of California. Correio eletrônico: saulofilhocds@gmail.com. Orcid: https://orcid.org/0000-0001-5937-8874

4 Biólogo / Doutor em Geografia, Universidade Federal Fluminense, Brasil. Centro de Desenvolvimento Sustentável da UnB, Professor Titular Coordenador Executivo do Projeto INCT-ODISSEIA "Observatório das Dinâmicas Socioambientais" Vice-Diretor do Instituto de Ciências Biológicas da UnB. Correio eletrônico: carlos.h.saito@hotmail.com. Orcid: https://orcid.org/0000-0002-5757-9629

5 Engenheiro Florestal / Doutor em Desenvolvimento Sustentável, Universidade de Brasília UNB, Brasil. Pesquisador, Centro de Desenvolvimento Sustentável da UnB. Correio eletrônico: romerogomes1@gmail.com, Orcid: https://orcid.org/0000-0002- 4553-3498

6 Economista / Doutoranda em Ambiente e Sustentabilidade, Universidade Nova de Lisboa, Portugal. Pesquisadora, Centro de Desenvolvimento Sustentável da UnB. Correio eletrônico: dri.michels@gmail.com, Orcid: https://orcid.org/0000-0003-2235-6174

7 Bacharel em relações internacionais / Mestre em Desenvolvimento Sustentável, Universidade de Brasília UNB, Brasil. Pesquisadora, Centro de Desenvolvimento Sustentável da UnB. Correio eletrônico: anaclaud.al@gmail.com. Orcid: https://orcid.org/0000- 0001-8469-4633 
fundiárias e facilitar os processos de delimitação e reconhecimento de terras.

Palavras chave. Povo Tuxá; Pankararu; mudanças climáticas; segurança alimentar.

\begin{abstract}
Due to climate change and desertification, significant reductions in food production in various regions of the world are expected in the coming decades. The most impacted will be the poorest populations, especially communities that have small plots of land and are dependent on climatic conditions. This article shows how the land factor, drought, income and the increase of the self-declared indigenous population
\end{abstract}

\section{Introdução}

Com uma área de, aproximadamente, $155.637 \mathrm{~km}^{2}$, o Submédio São Francisco (SubM-SF) abrange uma totalidade de $17 \%$ do território da bacia hidrográfica do rio São Francisco. [1] Nessa região, a topografia e a vegetação são variadas, no entanto, seu clima a coloca como uma das mais hostis para ocupação humana devido a seus baixos índices de ocorrência de chuvas, baixa disponibilidade hídrica e altas temperaturas.

O SubM-SF é considerado tanto um hotspot de mudanças do clima (MC) como de vulnerabilidade às MC. As Projeções climáticas do Painel Brasileiro de Mudanças Climáticas (PBMC) apontam um aquecimento entre $1,5^{\circ} \mathrm{C}$, em um cenário otimista, e $5^{\circ} \mathrm{C}$, no cenário mais pessimista até o ano de 2100, com intensificação das secas e diminuição da disponibilidade de água para o consumo humano, animal e vegetal.[2] Estes impactos aos sistemas socioecológicos (SSE) no SubM-SF afetam os modos de vida e as atividades produtivas das comunidades tradicionais que dependem dos regimes de precipitação e dos serviços ecossistêmicos da Caatinga - bioma predominante na região. [3] place the Tuxá and Pankararu indigenous peoples in a vulnerable situation. It is shown that the increase of the indigenous population and the extreme events caused by climate change may compromise the future of the cultivation of the main agricultural crops of these peoples, among them beans, rice, cassava and maize, reducing the possibility of guaranteeing their food, social union and reproduction. Brazil's indigenous population has shown an interesting increase, but in parallel tothis fact, the planting areas have been shrinking, which obliges decision makers to reduce land problems and facilitate land delimitation and recognition processes.

Key words. Tuxá People; Pankararue; climate changes; food security.

Contrariando as narrativas de escassez difundidas sobre a região, o Submédio São Francisco concentra uma grande riqueza na diversidade de povos indígenas, que até hoje vêm sofrendo uma série de injustiças socioeconômicas e ambientais, obrigando-os a lutar cada dia mais por sua sobrevivência em contextos de disputas pelas terras e mobilizações sociopolíticas para conquista e garantia de direitos sociais.

A expropriação das terras indígenas perpassa toda a história do Brasil, sendo que, nos últimos 50 anos, observa-se na literatura o agravamento desse processo no SubM-SF, a partir de duas frentes, a primeira pela ocupação de grandes fazendeiros e o acelerado crescimento da fronteira agrícola, e a segunda, durante o processo de construção das hidrelétricas Sobradinho, Itaparica, Moxotó, Paulo Afonso e Xingó, dando origem aos atingidos por barragens. ${ }^{1}$

1 Expropriados, deslocados, afetados e atingidos são algumas das designações que, no decorrer do tempo, foram utilizadas para identificar as populações atingidas pela construção de uma barragem. Os impactos sociais e ambientais decorrentes da implementação das barragens e o conceito de atingido por barragem são abordados em diferentes estudos. [38][39][40][41][42][43] 
Estes dois aspectos - condições climáticas que se agravam ano após ano na região e a reduzida disponibilidade de terra - vêm limitando a produção agrícola para consumo e comercialização e a criação de animais, restringindo desta forma a possibilidade de garantir uma vida digna de acordo aos princípios socioculturais de cada povo.

Nesse contexto, o artigo tem por finalidade discutir a situação que atravessam as etnias Tuxás e Pankararu no SubM-SF. Ao contrário de outros grupos sociais e povos indígenas da região, estes encontram-se numa situação de exposição, sensibilidade e baixa capacidade adaptativa, exacerbada pela construção das barragens, o avanço da fronteira agrícola e o crescimento populacional. Assim, torna-se indispensável incentivar o desenho e a incorporação de projetos ou políticas que permitam diminuir as deficiências existentes e promover melhorias na qualidade de vida a partir das demandas e especificidades desses povos.

Segundo Lindoso e Rodrigues-Filho (2016), a vulnerabilidade é função de três atributos: exposição, sensibilidade - que indicam a suscetibilidade dos sistemas aos impactos e riscos climáticos - e capacidade adaptativa (CA), que reflete as condições ou as possibilidades em lidar com esses

Expropriados, deslocados, afetados e atingidos são algumas das designações que, no decorrer do tempo, foram utilizadas para identificar as populações atingidas pela construção de uma barragem. Os impactos sociais e ambientais decorrentes da implementação das barragens e o conceito de atingido por barragem são abordados em diferentes estudos. [38][39][40][41][42][43]

impactos e riscos, pelo ajuste às mudanças que ocasionam (adaptação). A CA dos sistemas socioecológicos (SSE) frequentemente está relacionada a formulação e implementação de políticas públicas (PPs). [4]
As PPs, sejam implementadas por instituições do estado (da escala local à nacional) ou pela cooperação internacional, constituem-se em fator de auxilio e possibilita a adaptação às MC. No entanto, no Brasil observa-se atualmente um retrocesso no investimento em políticas públicas, especialmente na escala nacional que incluem, por exemplo, a reestruturação e deslocamento de responsabilidades de órgãos importantes como a Fundação Nacional do Índio (FUNAI) e o desmonte de PPs específicas para os povos indígenas. [5]

No início de 2019, a FUNAI foi subordinada ao Ministério da Mulher, da Família e dos Direitos Humanos, retornando em junho do corrente ano para o Ministério da Justiça com seu possível deslocamento para o Ministério da Agricultura. As mudanças na FUNAI apontam um processo de desarticulação da demarcação de terras indígenas, atendendo prioritariamente a interesses de grupos específicos (a exemplo da agricultura de larga escala, mineradoras e setor de energia) no contexto de pressão por apropriação de terras e exacerbação de conflitos fundiários. A discussão feita no presente trabalho indica o papel das PPs e das mudanças institucionais na configuração de um quadro de vulnerabilidade dos povos indígenas, especialmente à medida que modificam o acesso e direito à terra.

\section{Material e Métodos}

A Rede Brasileira de Pesquisas em Mudanças Climáticas (REDE CLIMA) e o Observatório das Dinâmicas Socioambientais (INCT - Odisseia) realizaram entre 2017 a 2018 pesquisas de campo

junto aos povos indígenas e comunidades tradicionais no SubM-SF, nos estados da Bahia e Pernambuco. Região que corresponde a uma das 4 regiões fisiográficas da Bacia Hidrográfica do rio São Francisco (BHSF). ${ }^{2}$

2 Esta área corresponde a $17 \%$ da Bacia, que integralmente se localiza no Semiárido da região Nordeste do Brasil. 
As pesquisas de campo realizadas integraram o uso de técnicas qualitativas para o levantamento de dados primários (como entrevistas semi-estruturadas e grupos focais ou oficinas participativas), como também técnicas quantitativas para o levantamento de dados secundários. Ambas informações foram analisadas e cruzadas com a finalidade de validar e consolidar a informação exposta. [6][7][8]

Destaca-se que o delineamento da pesquisa foi realizado junto a instituições, lideranças e outros atores locais, que representam o SubM-SF na escala nacional, regional e local. Para este fim, foram adotados processos de articulação (reuniões, seminários e oficinas de trabalho prévios). Entre as instituições, dialogou-se com representantes da Articulação dos Povos e Organizações Indígenas do Nordeste, Minas Gerais e Espírito Santo (APOINME), Articulação no Semiárido Brasileiro (ASA), Comitê de Bacia Hidrográfica do Rio São Francisco (CBHSF), Agência Peixe Vivo, Empresa Brasileira de Pesquisa Agropecuária (EMBRAPA Semiárido), Universidade Federal do Vale do São Francisco (UNIVASF), Ministério do Meio Ambiente (MMA), Ministério de Saúde (MS) e Ministério do Desenvolvimento Social e Combate à Fome (MDS).

Com base no exposto, o presente artigo analisa a situação dos povos indígenas Tuxás (na Bahia) e Pankararus (em Pernambuco) e para tanto, utiliza 23 entrevistas semiestruturadas realizadas com

Esta área corresponde a $17 \%$ da Bacia, que integralmente se localiza no Semiárido da região Nordeste do Brasil.

representantes dessas etnias, entre os anos de 2017 e 2018. O estudo também aborda as percepções destes povos sobre os impactos da última seca (20102017), a sua segurança socioambiental e as ações e os processos decisórios para sua superação.

Em 2018 foi realizada uma oficina participativa na aldeia mãe dos Tuxás (em D’zorobabé, localidade também conhecida como Surubabel, Bahia) que contou com a participação de cerca de 30 lideranças indígenas. Esta teve por objetivo pactuar os resultados preliminares obtidos pela REDE CLIMA, e coletar novos fatos. Na (Figura 1) constam o recorte geográfico da área de estudo, assim como a espacialização das entrevistas e oficinas realizadas.

Destaca-se que as entrevistas e oficinas com os Tuxás contou com a participação do Pajé, Caciques e Conselheiros das Aldeias, sendo estes os maiores representantes de aproximadamente três mil pessoas hoje assentadas no território indígena.

A análise das entrevistas apoiou-se em: i) leituras sucessivas das narrativas dos atores a partir das transcrições das entrevistas e anotações de campo, a fim de identificar dados e percepções-chaves sobre cada tema; ii) sistematização das informações de campo com base nos atributos da vulnerabilidade - exposição; sensibilidade; e, capacidade adaptativa; iii) análise das percepções- chaves à luz de abordagens conceituais e empíricas da literatura científica.

Em relação às análises de estiagem do Nordeste e à produção do gráfico histórico de estiagem no Nordeste, foi realizado uma pesquisa bibliográfica [9] [10][11][12][13][14]. Os dados relatados de seca foram organizados por ano e quantificado numa tabela. Na etapa seguinte, foi comparado com o levantamento histórico de Machado, Dias, \& Silva (2017), onde se obteve poucas divergências, sendo a tabela ajustada, complementada e o gráfico gerado. Nos dados onde ocorreram divergências, foram mantidos os dados coletados na pesquisa bibliográfica.[15]

Finalmente, importante destacar que a pesquisa foi aprovada pelo Comitê de Ética em Pesquisa em Ciências Humanas e Sociais da Universidade de Brasília (UnB) - processo que se encontra devidamente avaliado e protocolizado. ${ }^{3}$

3 O processo encontra-se registrado com o seguinte número 98071318.0.0000.5540 


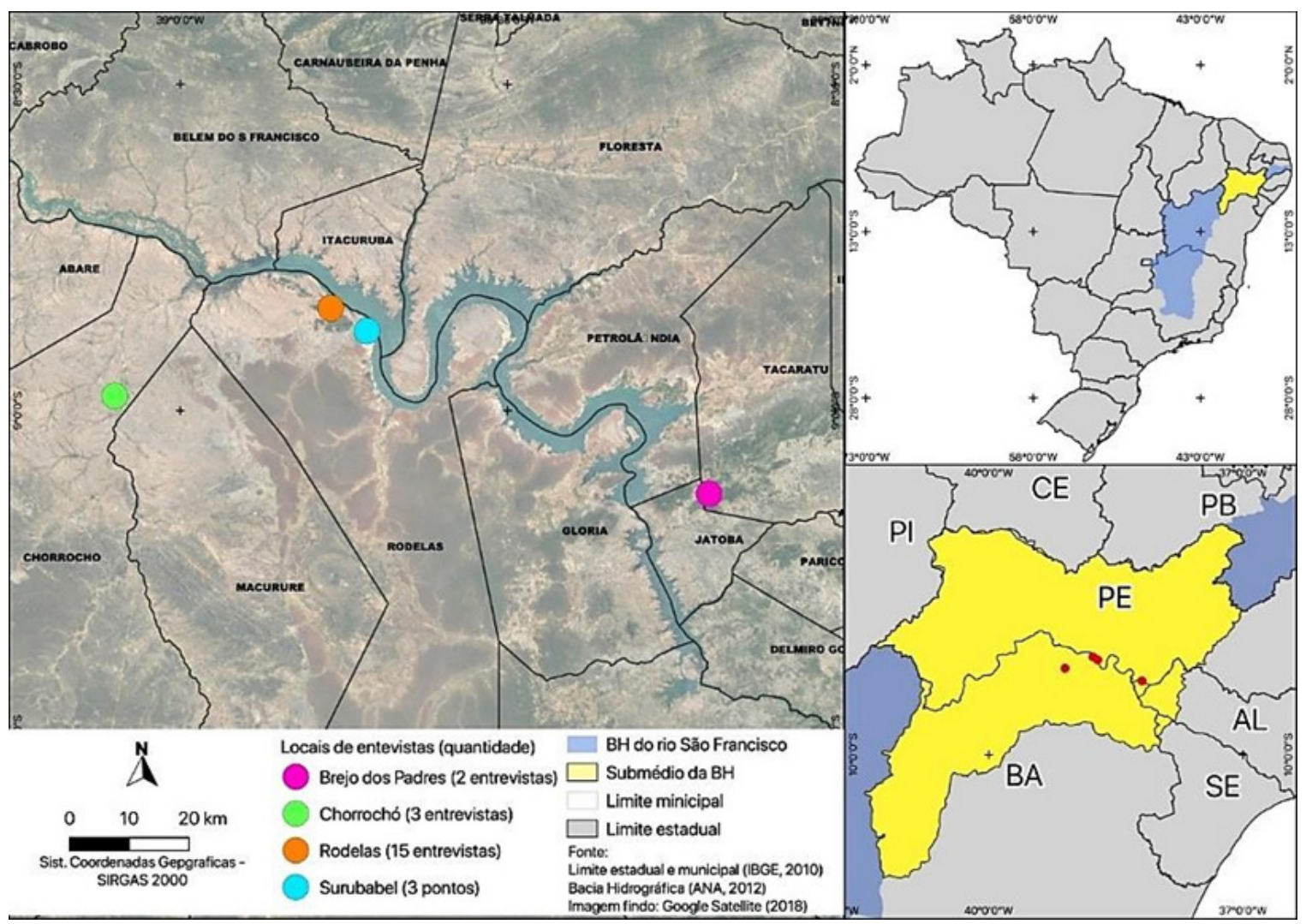

Figura 1. Espacialização das entrevistas semiestruturadas no Submédio São Francisco.

Fonte: elaboração dos autores, 2019.

\section{Resultados e Discussão.}

\subsection{Os povos indígenas no SubM-SF}

Segundo o Censo Demográfico de 2010, [16] o Brasil possui uma população de 817.963 indígenas, pertencentes a 305 etnias. Na região do SubM-SF, segundo Prado (2012), residem aproximadamente trinta e oito povos indígenas, que em sua maioria encontram-se assentados na margem do rio São Francisco. [17]

A presença do indígena no Brasil, ano após ano, está se tornando mais evidente. Segundo dados do (IBGE, 2010) a partir dos Censos Demográficos para 1991, em 34,5\% dos municípios brasileiros residia pelo menos um indígena autodeclarado, já para o Censo Demográfico do ano 2000, esse número alcançou um 63,5\%, incrementando-se consideravelmente para o ano de 2010, atingindo a $80,5 \%$ dos municípios brasileiros. Afirma-se que o espalhamento da população indígena foi mais significativa na Região Nordeste. ${ }^{4}$

4 São diferentes as razões atribuídas ao crescimento populacional indígena no país. Para alguns autores o incremento deve-se ao processo de etnogênese, para outros, à geração de maiores incentivos governamentais e políticas públicas criados na última década no país. [44] Define-se como "etnogênese" ao processo de emergência de novas identidades como forma de reinvenção de etnias já reconhecidas.[45] Processo de assumir e reafirmar características culturais tradicionais por parte dos povos indígenas.[44] Segundo Dados do IBGE (2010), a população indígena brasileira aumentou $150 \%$ na década de 90, passando de 294 mil pessoas para $734 \mathrm{mil}$, de acordo com uma pesquisa divulgada pelo Instituto Brasileiro de Geografia e Estatística (IBGE). Afirmase que o crescimento médio anual registrado foi de $10,8 \%$, quase seis vezes maior do que o da população brasileira em geral. Em 1991, a percentagem de indígenas em relação à população total brasileira era de $0,2 \%$, subindo para $0,4 \%$ no ano 2000 . 
Cada povo mantém diferentes práticas culturais, conhecimentos e cosmovisões, elementos que os caracteriza, e outorga identidade e representatividade. Manter estas características culturais, para muitos, foi uma luta, já que o processo de colonização, ao mesmo tempo que esbulhou as terras dos indígenas, os afastou de suas práticas culturais. Darcy Ribeiro (1986) analisando o processo histórico dos esbulhos das terras indígenas no país e sertão do nordeste, afirmou que em razão da expulsão dos seus territórios, os índios se dispersaram, vivendo, no início do século XX, perambulando pelas fazendas e nas margens do São Francisco à procura de comida. Afirma-se que o indígena nordestino, após perderem suas terras encontrava-se ilhado em meio da população nacional, vivendo como reserva de mão-de-obra, habitando pequenas parcelas de terras, mas dispersos na dependência e miséria.[18]

Essa situação deu lugar a uma miscigenação do indígena, principalmente na região do nordeste, produzindo o surgimento dos chamados caboclos, identidade que muitas vezes era assumida poreles mesmos para esconder a identidade étnica diante das inúmeras perseguições. ${ }^{5}$ [19][20] No entanto, a

São diferentes as razões atribuídas ao crescimento populacional indígena no país. Para alguns autores o incremento deve-se ao processo de etnogênese, para outros, à geração de maiores incentivos governamentais e políticas públicas criados na última década no país. [44] Define-se como "etnogênese" ao processo de emergência de novas identidades como forma de reinvenção de etnias já reconhecidas. [45] Processo de assumir e reafirmar características culturais tradicionais por parte dos povos

5 Segundo (SILVA, 1996), na região Nordeste, sobretudo após a Lei de Terras de 1850 que determinou os registros cartoriais das propriedades e definiu a venda das terras públicas em leilões, os senhores de engenho no litoral e autoridades que possuíam interesses comuns, afirmaram durante décadas que os índios estavam confundidos com a massa da população, não existindo mais razão de dar continuidade aos aldeamentos. Este fato teria provocado o acrescentamento de invasões e a diminuição de interesse por parte dos órgãos nacionais em reconhecer as terras do indígena nordestino. indígenas. [44] Segundo Dados do IBGE (2010), a população indígena brasileira aumentou $150 \%$ na década de 90, passando de 294 mil pessoas para 734 mil, de acordo com uma pesquisa divulgada pelo Instituto Brasileiro de Geografia e Estatística (IBGE). Afirma-se que o crescimento médio anual registrado foi de $10,8 \%$, quase seis vezes maior do que o da população brasileira em geral. Em 1991, a percentagem de indígenas em relação à população total brasileira era de $0,2 \%$, subindo para $0,4 \%$ no ano 2000.

Segundo (SILVA, 1996), na região Nordeste, sobretudo após a Lei de Terras de 1850 que determinou os registros cartoriais das propriedades e definiu a venda das terras públicas em leilões, os senhores de engenho no litoral e autoridades que possuíam interesses comuns, afirmaram durante décadas que os índios estavam confundidos com a massa da população, não existindo mais razão de dar continuidade aos aldeamentos. Este fato teria provocado o acrescentamento de invasões e a diminuição de interesse por parte dos órgãos nacionais em reconhecer as terras do indígena nordestino.

criação de instituições públicas como o Serviço de Proteção aos Índios (SPI), a Fundação Nacional do Índio (FUNAI), a Secretaria Especial de Saúde Indígena (SESAI), entre outros, que brindam apoio ao indígena, reafirmou a sua presença nesta região do País, permitindo-lhes, desde as primeiras décadas do Século XX, retomar mobilizações e conquistar um reconhecimento do Estado brasileiro.

Mesmo que na atualidade existam instituições que respaldem e zelem pelos direitos indígenas, estes não garantem a sua convivência com outros grupos da sociedade, que como no passado disputam territórios e recursos naturais que se tornam cada vez mais escassos. Melo (1980), afirma que nas regiões agreste e sertão, atualmente denominadas de semiárido nordestino, as disputas pelos espaços úmidos e fontes de água sempre foram intensas, que se agravavam segundo as características da região. 
[21] Por exemplo, afirma-se que a ocupação dos brejos, pequenas áreas isoladas semelhantes ao litoral úmido, vem provocando o conflito constante entre seus assentados, devido a que estas áreas possuem solos profundos, matas de serras e cursos de água permanentes. Estas condições favoreceriam a policultura, horticultura e fruticultura tradicional, atividades que atualmente os indígenas destas regiões procuram realizar para garantir sua alimentação e comercialização.

\section{Os povos Indígenas Tuxá e Pankararu. Rasgos culturais e situação atual}

O Povo Tuxá autoidentifica-se como membros da nação Proká, remanescente das etnias que conformam as missões do Nordeste do rio São Francisco no século XVII. [22][23][24] Na atualidade o povo encontra-se disperso em aldeias e assentamentos situados nos estados de Pernambuco, Bahia, Alagoas e Minas Gerais. ${ }^{6}[20]$ O povo Tuxá costuma viver em grupos de famílias nucleares e preserva a sua tradicional representação vertical, conformada pelo pajé e caciques.

O povo perdeu grande parte da sua língua materna e outros elementos importantes de sua tradição, com exceção do ritual Toré. Para os povos indígenas do Nordeste, o Toré é o seu principal ritual, envolve a dança e o canto para comemorar e agradecer, constituindo-se num sinal de identidade étnica e de coesão tribal, que promove a assimilação, reafirmação e a integração. [25][26]

Os Tuxá é um povo tradicionalmente agricultor e pesqueiro, no entanto, estas atividades que costumavam ser realizadas por grande parte da população indígena, nas terras que habitavam e nas margens

6 O Povo Tuxá após a construção da hidrelétrica Luiz Gonzaga (1988), dividiu-se; um grupo ficou nas margens do São Francisco próximos à cidade de Rodelas, e outro foi deslocado para Ibotirama, onde a população indígena recebeu terras. Os outros assentamentos indígenas, correspondem a remanescentes de familiares que assentaram-se ao longo do tempo após serem deslocados. do rio São Francisco, são a cada dia menos praticadas, devido fundamentalmente à falta de território e à diminuição abrupta do peixe no rio, levando a que muitos se dediquem quase de forma exclusiva a desenvolver trabalhos remunerados em qualquer rubro. ${ }^{7}$

O povo Pankararu encontra-se assentado em duas áreas dentro do estado Pernambucano, entre Serras e Jatobá. Neste último município encontra-se sua principal aldeia, Brejo dos Padres, que concentra aproximadamente 5.365 indígenas em uma área homologada de 8100 hectares. $^{8}$

Segundo membros do povo indígena, esta etnia ressurgiu da invasão dos colonizadores que tomaram suas terras do litoral nordestino para a produção de cana de açúcar e a criação de gado. Estudos margens do São Francisco próximos à cidade de Rodelas, e outro foi deslocado para Ibotirama, onde a população indígena recebeu terras. Os outros assentamentos indígenas, correspondem a remanescentes de familiares que assentaram-se ao longo do tempo após serem deslocados.

Em respeito à educação do povo indígena, afirma-se que o $98 \%$ da população em idade de estudar realiza seus estudos na escola indígena da comunidade. O centro educativo tornou-se num ícone para os indígenas devido este promover a reivindicação e recuperação das tradições do povo, abrir espaços de diálogo e luta, e formar reconhecidos representantes indígenas do país.

A Terra Indígena Pankararu, homologada em 1987, está localizada entre os atuais municípios de

7 Em respeito à educação do povo indígena, afirma-se que o 98\% da população em idade de estudar realiza seus estudos na escola indígena da comunidade. O centro educativo tornou-se num ícone para os indígenas devido este promover a reivindicação e recuperação das tradições do povo, abrir espaços de diálogo e luta, e formar reconhecidos representantes indígenas do país.

8 A Terra Indígena Pankararu, homologada em 1987, está localizada entre os atuais municípios de Petrolândia, Itaparica e Tacaratu, no sertão pernambucano, próximo ao rio São Francisco.[46] 
Petrolândia, Itaparica e Tacaratu, no sertão pernambucano, próximo ao rio São Francisco.[46]

antropológicos indicam que a formação das primeiras aldeias dos Pankararu foram constituídas por missionários que os encontraram, por razões de sobrevivências, penetrados na caatinga..$^{9}[27]$

Devido a este fator, os Pankararu atravessaram processos de mestiçagem bastante fortes, razão pela qual, somada às proibições das que foram vítimas, perderam quase por completo a sua língua materna. Porém, possuem um sentimento de pertencimento e ancestralidade pré-colombiana bastante forte, se diferenciando em alguns aspectos de outros povos indígenas.

De forma similar aos Tuxás de Rodelas, o povo pratica o Toré como símbolo de reafirmação identitária, no entanto, dão maior importância às forças sobrenaturais dos encantados e seus conhecimentos cosmológicos.[28]

Os Pankararu em relação aos Tuxás de Rodelas, encontram-se numa situação fundiária favorável, por possuírem uma terra fértil devidamente reconhecida. Já no caso dos Tuxá, devido ao deslocamento que sofreram pela construção da hidrelétrica Luiz Gonzaga (1988), uma grande parte da população indígena ficou sem terra, ocasionando uma série de traumas socioculturais que se expõe a continuação.

\section{A perda dos territórios indígenas e seu impacto}

Grande parte dos povos indígenas do Nordeste continuam vivenciando conflitos fundiários que em muitos casos atenta contra a vida das lideranças indígenas, um processo recorrente para estas sociedades historicamente subjugadas.

9 Afirma-se que após o assentamento os indígenas percorriam o SubM-SF que incluía a cachoeira de Paulo Afonso, BA, a cachoeira de Itaparica, PE até as margens do rio Moxotó.
Como foi observado, muitos destes povos, por uma questão de refúgio e sobrevivência, deslocaram- se à região do Submédio do São Francisco em tempos da colonização, dando origem aos aldeamentos, que em alguns casos foram reconhecidos pelo Estado Brasileiro. No entanto, quando país deu curso a uma política de desenvolvimento e progresso do Nordeste, implementou-se a construção de usinas hidroelétricas durante o século XX.

O Rio São Francisco tem uma extensão de 3.200 km, contudo, afirma-se que atualmente, partindo do lago da UHE Três Marias, ele possui apenas dois trechos de águas correntes, correspondendo a $1.100 \mathrm{~km}$ entre as barragens de Três Marias e Sobradinho e 280 km da barragem de Sobradinho até a entrada do reservatório de Luís Gonzaga. Transforma-se, assim, o percurso rio abaixo em uma diversidade de represas. ${ }^{10}[29]$

A construção das hidrelétricas Sobradinho, Itaparica, Moxotó, Paulo Afonso e Xingó, que aconteceu nos últimos 50 anos, provocou um número importante de danos ambientais e sociais provocados pela ocupação da água e os deslocamentos forçados da população tradicional. O povo Tuxá a mais de 35 anos habitou 30 ilhas que existiam no Submédio do rio São Francisco (Ver Figura 2), afirma-se que estas encontravam-se entre Chorrochó (Barra do Tarrachil) e o Rio Pajeú. [30] Após a construção da Barragem de Itaparica (1988), atualmente chamada de UHE Luiz Gonzaga, estas foram submersas pelas águas do Rio. ${ }^{11}$

10 Tal condição produz impacto direto na composição e população do pescado, interferindo diretamente na atividade pesqueira. A regularização da vazão do rio controla as enchentes e consequentemente impede a fertilização de suas margens. [43

11 A construção da barragem iniciou-se por volta de 1977 reassentando os indígenas em 1985 e 1986 à margem das cidades baianas (Rodelas e Ibotirama). O grupo que ficou em Rodelas não foi beneficiado com terras, por tanto ainda espera alguma compensação pela perda. Já o grupo que foi para Ibotirama recebeu terras que hoje são usadas para agricultura do povo. A inundação do território Tuxá, afirma-se, provocou a perda das seguintes Ilhas: ilha do Peixinho, ilha do Sabonete, ilha Cambaingá, ilha do Cupim, ilha Tucun, ilha da Porta, ilha da Cobra, ilha do Rodrigues, ilha do Coité, ilha de Surubabel, ilha do Coitezinho, ilha do Fubá, ilha do Serrote, ilha do Urubu e a mais importante a Viúva. Segundo estudos, afirma-se que o território que compunha a terra original dos índios Tuxá correspondia a uma área aproximada de 1.600 hectares. [30] 


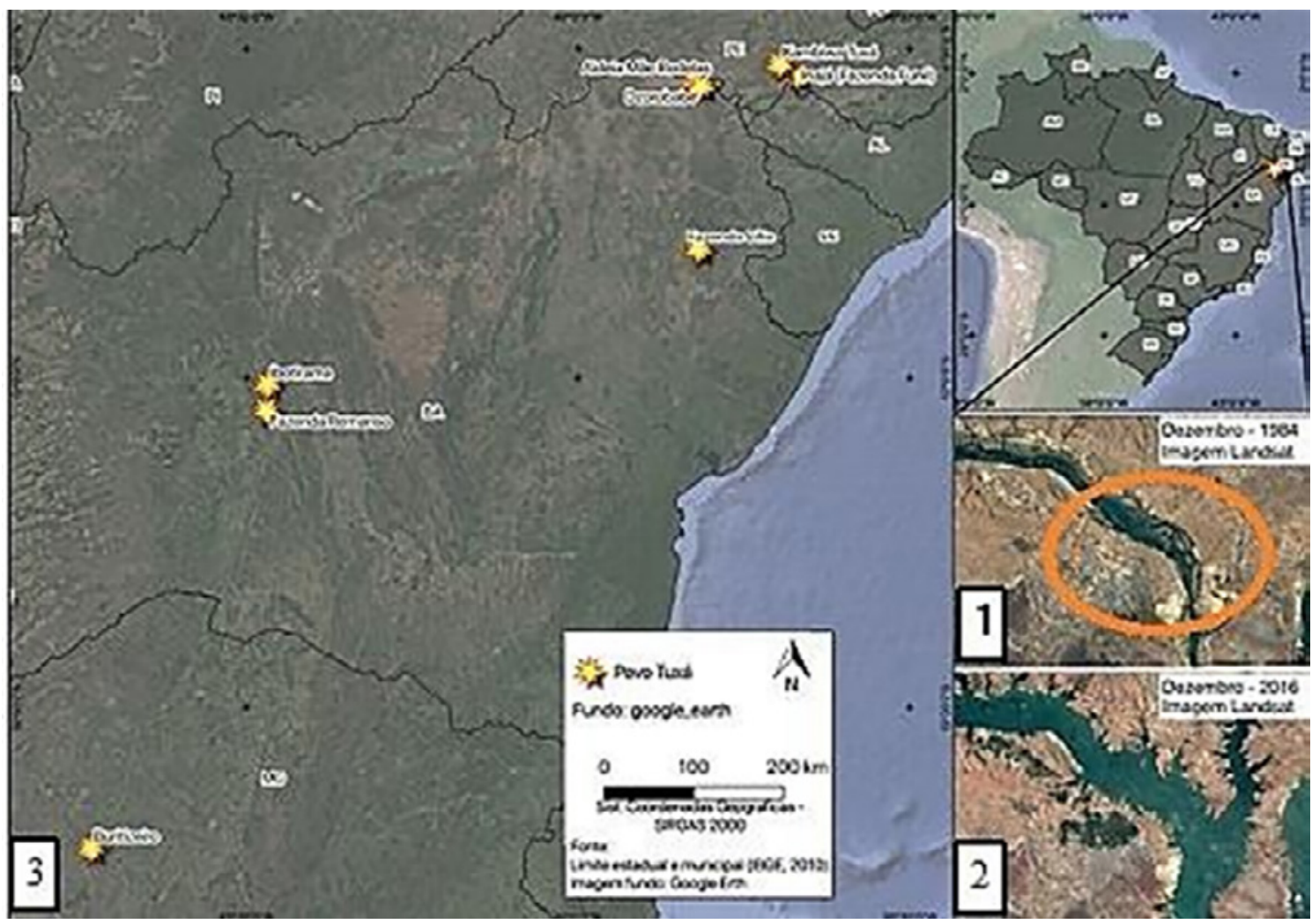

Figura 2. 1) Identificação das terras Tuxá perdidas pela enchente do Rio São Francisco após a construção da Hidrelétrica Itaparica. 2) Rio São Francisco do Sub meio após a construção da UH. 3) Deslocamento Tuxá no Brasil

Fonte. Elaboração dos autores, 2019.

A construção da Hidrelétrica de Itaparica é um acontecimento crucial para entender a atual conjuntura dos Tuxá: esta modificou drasticamente a paisagem local e o modo de vida do povo, que dedicou-se historicamente à pesca e agricultura. Estas atividades, segundo eles, hoje diminuíram consideravelmente, provocando fome e miséria em algumas famílias indígenas.

Alguns membros da etnia afirmam que antigamente sua alimentação dependia da produção que se tinha nas ilhas perdidas, onde adicionava-se proteínas provenientes da caça e pesca à refeição diária. Essas atividades, hoje, perderam-se, devido à falta de terras e a abrupta redução de animais no território.

“...Então eu lembro que minha avó falava que meu avô quando voltava do trabalho ia pescar a janta, ia pescar e sempre pegava. Então tinha-se certeza que a janta ia chegar, que ia comer algo. Nunca se passou fome naqueles tempos, você tinha a mandioca, batata, tinha aqueles estoques para se alimentar e só pegava o peixe, aí tinha o refeitório completo. Hoje você sai para pegar algo no rio e não consegue, já não tem mais como você confiar no que o rio pode Ihe brindar, tem que sair para trabalhar e comprar (...). A gente vive ainda de pesca (...) hoje você vai para o rio para tentar pescar e não pega nada, isso é preocupante, o rio não dá mais o que antigamente ele nos dava. Meu Marido saiu três, quatro vezes já para tentar pescar, pegou 2/3 peixes ficando lá o dia todo. O peixe tem gosto diferente e fede também, é diferente, tem peixe ainda, quando chove mais, só quando chove e também a água sai preta ou os peixes morrem..."

\section{Depoimentos de moradores da Aldeia Tuxá} em Rodelas (2018) 
Por outro lado, afirma-se que este fato provocou algo ainda mais importante, o afastamento de seus ancestrais e território religioso, valores étnicos e simbólicos que encontravam-se naquela que um dia foi sua principal ilha, a Viúva ou ilha mãe. ${ }^{12}$

O povo Pankararu não sofreu, como os Tuxá, a perda de território provocado pelo alagamento das hidrelétricas, já que os territórios que antigamente lhes pertencia encontravam-se ocupados por fazendeiros. O povo Pankararu foi um dos primeiros povos indígenas do país que obteve o reconhecimento da sua terra, homologada em 1987. No entanto, hoje essas parcelas ainda estão ocupadas por posseiros (ISA, 2017). Em 13 de Setembro do 2018 o Tribunal Regional Federal da 5a. Região (TRF-5) determinou a desocupação dos posseiros o que provocou reações violentas por parte dos afetados.

\subsection{Conflitos sociais por questões fundiárias e desinstitucionalização indígena}

No mês de dezembro do 2018 o povo Pankararu sofreu com o incêndio criminoso de três estabelecimentos da comunidade, a igreja, a escola e seu posto de saúde. Para os indígenas, estes fatos

- que vêm se tornando mais recorrentes em todo o país - são o resultado do clima político que se vivencia, evidenciando o repúdio que alguns grupos da sociedade brasileira têm sobre a presença indígena na região.[31][32]

No mesmo período, o povo Tuxá também foi vítima de ameaças por parte de moradores da cidade de Rodelas. Um grupo de moradores não-indígena

12 O território é o entrecruzamento do tempo com espaço a partir de memórias e imaginários territoriais. Esta forma parte de um sinal cujo significado só é compreensível desde os códigos culturais nos quais se inscreve. Um território concentra grupos sociais e sua conexão e dinâmica permite o desenvolvimento de costumes e culturas específicas. O território, ao contrário do espaço físico, tem uma significação cultural e implicações sociais, onde se estabelecem práticas sociais com interesses distintos, com percepções, valorações e atitudes territoriais diferentes, que geram relações de complementação, de reciprocidade, mas também, de confrontação. [47][48] juntou-se nas portas da aldeia demandando o fim do processo de demarcação sobre D'zorobabé, território ancestral nas proximidades da sede do município que os Tuxá ocuparam e vem reivindicando.

Como os Tuxá e Pankararu, muitos povos do Brasil vêm sofrendo uma série de ameaças por causas fundiárias ou muitos estão cada vez mais longe de conseguir que suas terras sejam demarcadas. $\mathrm{O}$ discurso contraindigenista proclamado pelo atual presidente da República e parte do seu gabinete, vem prejudicando o reconhecimento histórico da dívida existente aos povos, assim como, da deliberação das demarcações de terras indígenas.

A isso, soma-se o processo de deslegitimação e deslocamento de gestão da Fundação Nacional do Índio (Funai), empoderando promotores de movimentos de incursões nas terras indígenas e estabelecimento de assentamentos ilegais, reduzindo a capacidade dos povos para adquirir seus direitos fundiários. ${ }^{13}$ Estes fatos vêm colocando os diferentes povos do Submédio do São Francisco e do país em uma situação de vulnerabilidade ainda maior, devido a questão fundiária se constituir num elemento importante da reprodução social e de identidade cultural, mas fundamentalmente, da sobrevivência. Portanto, medidas devem ser adotadas para garantir os direitos dos povos, assim como a sua sobrevivência.

No mundo, muitos povos ainda são dependentes das ocorrências de chuvas para a sua produção, colocando-os ainda mais em uma situação de vulnerabilidade diante os efeitos das mudanças climáticas, contudo, adicionar esta problemática aqueles que hoje dispõem pequenas parcelas de terra em áreas áridas, coloca em risco o seu desenvolvimento humano, assim como a sua segurança hídrica e alimentar.

13 A princípios deste ano a FUNAI foi subordinada ao Ministério da Mulher, da Família e dos Direitos Humanos, voltando o mês passado para as competências do Ministério da Justiça, mostrando com isso a existência de um objetivo amplamente cobiçado entorno à ocupação de terras e inviabilizando a sua demarcação e entrega para os indígenas, colocando uma vez mais os povos do país numa situação de desamparo e emergência. 


\section{A variabilidade climática no SubM-SF e projeções}

A região do SubM-SF, caracteriza-se pela escassez de água, pelos extremos climáticos e pelos regimes de precipitações pouco previsíveis, com elevada evapotranspiração. Períodos de estiagem têm sido relatados no Nordeste do Brasil desde o século XVI. [9][10] [11][14] A (Figura 3) mostra um resumo desses eventos, atualizados até 2017.

Observa-se que a última estiagem (2012-2017) foi uma das mais longas do último século. Marengo et al. (2016), afirmam que no Nordeste do Brasil os sinais de seca começaram a aparecer em dezembro de 2011 e se intensificaram durante o verão e outono de 2012, gerando deficiência hídrica em quase todo o semiárido, desde o centro-sul da Bahia até o Rio Grande do Norte e Ceara em 2011-14. Afirmase que desde 2013 até 2015 a maior concentração de déficit hídrico incluiu particularmente o norte da Bahia, oeste do Pernambuco e o leste do Piauí, onde a situação de seca ainda persiste.

A extensão e a intensidade dessa estiagem afetaram a economia regional do semiárido e refletiu nos níveis de vazão da Bacia do rio São Francisco. ${ }^{14}$ Segundo estudos, as estações chuvosas da região desde o ano de 2012 até 2016 foram as mais deficitárias desde 1961, tornando-se cada vez menor a quantidade de chuva e, a cada período, a área mais seca.[14]

Representantes e povoadores indígenas Tuxá e Pankararu, a esse respeito, percebem variações climáticas importantes. Estes afirmam que nos últimos anos tanto a chuva como a temperatura mudaram bastante. No primeiro caso, indicam que vivencia-se uma diminuição considerável de chuvas, assim como

14 Se indica que a vazão natural que entrava no reservatório de três Marias, em fevereiro de 2017, registrou- se em 71,9\% abaixo da média mensal de longo termo. Já no início de março de 2017, esse reservatório diminuiu para $32,7 \%$ de sua capacidade, afetando o abastecimento de 1.100 municípios, ocasionando a morte de vários animais e a perda de amplas extencoes de plantios. [14] do seu temporal, provocando a diminuição do Rio São Francisco e o acesso à água. Para eles este fato vem acompanhado de um abrupto incremento nas temperaturas da região, episódio que deu-se com mais intensidade nos últimos 10 anos, provocando a perda de plantios e produção de alimentos.

Rapaz mudou bastante, parece que a cada ano está ficando muito mais quente, e a chuva diminuiu muito, agora só poeira (...) Acho que a chuva aqui no nordeste diminuiu, eu de menino alcancei ver muita chuva aqui, porque o pessoal plantava até na catinga (...) Hoje você também vê um rio que está diminuindo, antigamente quando ficou preso você via por 10-15 anos o rio alto, agora não enche mais, ele está muito baixo, uma vez eu passei lá na frente na lapa, ai eu vi pessoal passando a pé, antigamente nunca passaram assim, o corredor do rio é profundo, ai vai tudo e tem a corrente forte, o corredor sempre foi profundo e ele nunca mais encheu. Está bem fraco (...) a gente ainda tinha algumas plantas que a gente estava cultivado na própria margem, com a seca essas plantas acabaram morrendo, e era plantas que colocamos tentando recuperar da mata ciliar. (...) o único ano que choveu bem foi esse ano, porque a gente estava com mais de seis anos aqui que a chuva estava quase cero, as nossas quatro nascentes que tínhamos aqui na serra acabou, esta desaparecendo (...). Então realmente a seca e o aumento da temperatura afetou muito, nós que somos índios buscamos também as águas que é uma das nossas tradições e cuidar as matas, o rio são Francisco. Esse é o nosso propósito e é o que a consequência da seca trouxe para gente, mas não conseguimos fazer nada frente a isso.

\section{Depoimentos de moradores da Aldeia Tuxá e Pankararu em Rodelas e Jatobá (2017/18)}

Como se observa os indígenas encontram-se preocupados pelas variações climáticas percebidas, afirmando que mesmo tentando realizar praticas que preservem o habitat onde moram, são incapazes de fazer frente aos efeitos adversos destas variações, originando na maioria dos casos prejuízos recorrentes. 


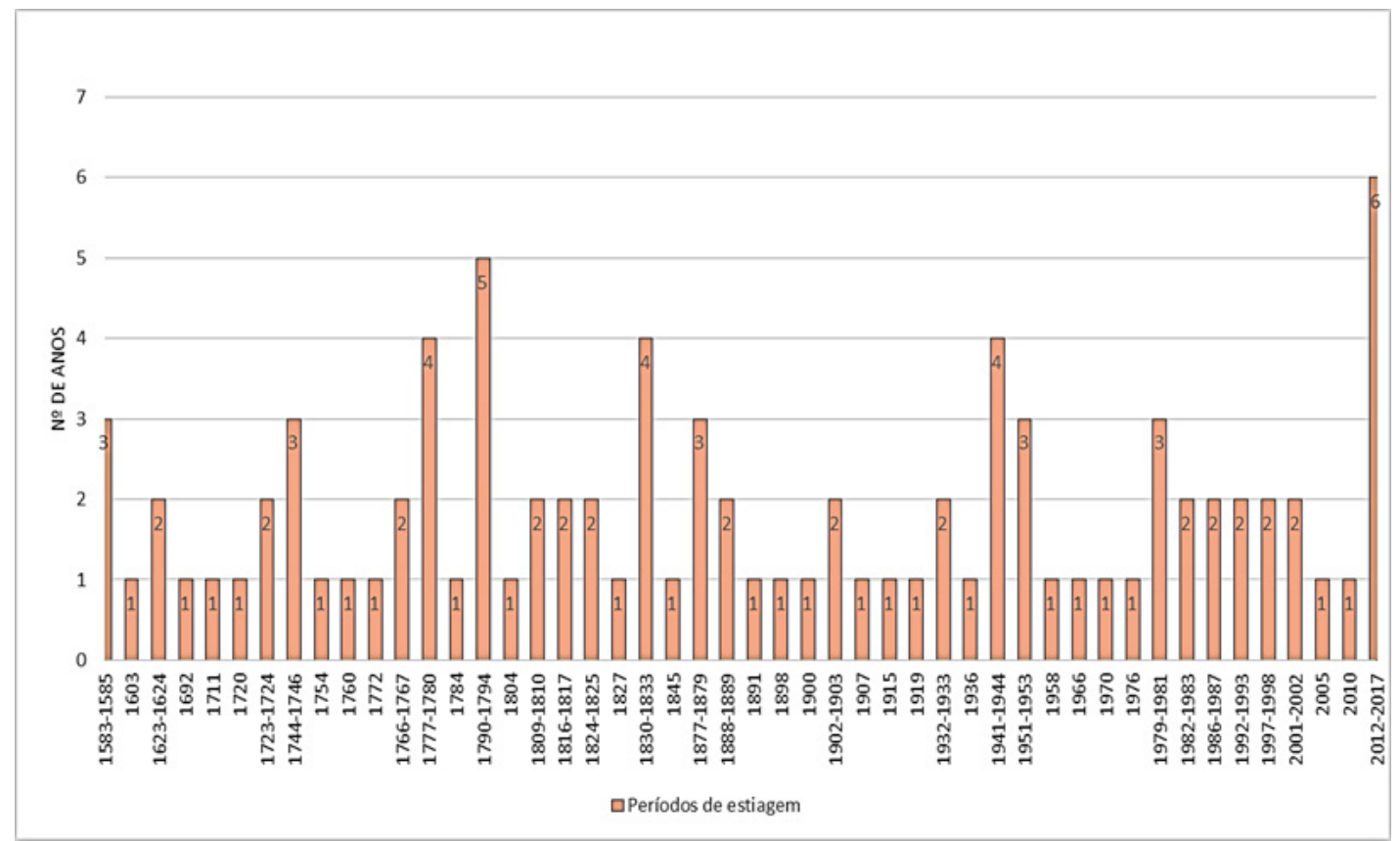

Figura 3. Série histórica de estiagens no Nordeste do Brasil -1583 a 2017.

Fonte: Adaptado de MOURA; SHUKLA, (1981), CARVALHO (2012), WILHITE et al (2014),

MARENGO et al (2016), MARENGO (2018).

Nesse sentido, se não são implementadas políticas de assistência aos povos em questão, as MC podem direcionar as diferentes populações do bioma Caatinga - predominante na região - para situações de vulnerabilidade extrema. Segundo modelos climáticos, a região estudada até o 2100 poderia registrar um aquecimento de $1,5^{\circ} \mathrm{C}$ em um cenário futuro otimista, e $5^{\circ} \mathrm{C}$ em um cenário pessimista, desatando uma série de problemas socioambientais ainda piores, que na atualidade muitos povos indígenas estão longe de enfrentar.[2]

\section{A falta de terra, mais um fator detonador de vulnerabilidade para os povos indígenas do SubM-SF}

Diferentes relatórios do IPCC prevêem que nas próximas décadas, por conta das mudanças climáticas, a produção de alimentos em todo o mundo pode sofrer uma considerável redução. [33] Segundo os cientistas do painel intergovernamental o aumento da temperatura ameaça o cultivo de várias plantas agrícolas, diminuindo a possibilidades de garantir a alimentação das famílias que moram nas áreas mais vulneráveis do planeta. ${ }^{15}$

O Brasil, segundo projeções realizadas para os cenários B2 e A2, poderia perder grandes extensões de território para a produção de Feijão, Arroz, Mandioca e Milho (Ver tabela 1). Calcula-se que até o ano de 2070, no cenário B2, aproximadamente 1,564 municípios do país poderiam se tornar inaptos para produzir estes produtos, causando uma série de problemáticas sociais e econômicas difíceis de superar. Para o cenário A2, a dimensão de perda seria ainda maior, já que calcula-se redução de produção em 1,608 municípios.

15 Afirma-se que os países pobres da África e da Ásia seriam os mais afetados, no entanto, países de américa do Sul e grandes produtores agrícolas como o Brasil também sentiriam os efeitos nas próximas décadas. [33] Afirma-se também que no mundo hoje aproximadamente 821 milhões de pessoas são subnutridos, 151 milhões de crianças menores de 5 anos são raquíticas e 613 milhões de mulheres entre 15 e 49 anos sofrem de deficiência de ferro (OB. CIT. 2019). 
Tabela 1. Projeções de impactos sobre a produção agrícola no país por efeitos das mudanças climáticas.

\begin{tabular}{|c|c|c|c|c|c|c|}
\hline \multirow{2}{*}{$\begin{array}{c}\text { Produtos / Áreas } \\
\text { Afetadas }\end{array}$} & \multirow{2}{*}{ Cenários } & \multicolumn{5}{|c|}{ Área potencial para plantio } \\
\hline & & 2006 & 2020 & 2050 & 2070 & Reduc. Total \\
\hline \multirow{5}{*}{$\begin{array}{c}\text { Feijão Nordeste } \\
\text { e Agreste. Sul do } \\
\text { Maranhão, Sul } \\
\text { do Piauí e Oeste } \\
\text { da Bahia }\end{array}$} & Cenário B2 & 4.137 .837 & 3.957 .481 & 3.723 .654 & 3.610 .276 & $-12,75 \%$ \\
\hline & Cenário A2 & 4.137 .837 & 3.957 .481 & 3.715 .178 & 3.587 .569 & $-13,30 \%$ \\
\hline & & \multicolumn{5}{|c|}{ Número de Municípios Produtores potencialmente afetados } \\
\hline & Cenário B2 & 4418 & 4038 & 3889 & 3818 & -600 \\
\hline & Cenário A2 & 4418 & 4030 & 3864 & 3778 & -640 \\
\hline \multirow{5}{*}{$\begin{array}{l}\text { Arroz Agreste } \\
\text { e regiões do } \\
\text { Cerrado nor- } \\
\text { destino, Sul do } \\
\text { Maranhão, o } \\
\text { sul do Piauí e o } \\
\text { Oeste da Bahia }\end{array}$} & Cenário B2 & 4.168 .806 & 3.812 .092 & 3.646 .396 & 3.572 .216 & $-14,31 \%$ \\
\hline & Cenário A2 & 4.168 .806 & 3.764 .488 & 3.655 .029 & 3.577 .169 & $-14,19 \%$ \\
\hline & & \multicolumn{5}{|c|}{ Número de Municípios Produtores potencialmente afetados } \\
\hline & Cenário B2 & 4.011 & 3966 & 3638 & 3.604 & -407 \\
\hline & Cenário A2 & 4.011 & 3712 & 3659 & 3.609 & -402 \\
\hline \multirow{5}{*}{$\begin{array}{c}\text { Mandioca Se- } \\
\text { miárido e no } \\
\text { e Agreste } \\
\text { nordestino, }\end{array}$} & Cenário B2 & 5.169 .601 & 5.040 .005 & 5.546 .241 & 6.028 .399 & $16,61 \%$ \\
\hline & Cenário A2 & 5.169 .601 & 5.006 .777 & 5.866 .398 & 6.268 .636 & $21,26 \%$ \\
\hline & & \multicolumn{5}{|c|}{ Número de Municípios Produtores potencialmente afetados } \\
\hline & Cenário B2 & 4.042 & 4119 & 4270 & 4.403 & 361 \\
\hline & Cenário A2 & 4.042 & 4252 & 4405 & 4.513 & 471 \\
\hline \multirow{5}{*}{$\begin{array}{c}\text { Milho O Agreste } \\
\text { nordestino, sul } \\
\text { do Maranhão, o } \\
\text { sul do Piauí e o } \\
\text { oeste da Bahia e } \\
\text { o Centro-Oeste } \\
\text { do país. }\end{array}$} & Cenário B2 & 4.381 .791 & 3.848 .384 & 3.718 .978 & 3.618 .258 & $-16,98 \%$ \\
\hline & Cenário A2 & 4.381 .791 & 3.856 .839 & 3.716 .684 & 3.624 .487 & $-17,28 \%$ \\
\hline & & \multicolumn{5}{|c|}{ Número de Municípios Produtores potencialmente afetados } \\
\hline & Cenário B2 & 4.365 & 3932 & 3860 & 3.808 & -557 \\
\hline & Cenário A2 & 4.365 & 3932 & 3844 & 3.799 & -566 \\
\hline
\end{tabular}

Fonte. Adaptação dos autores com dados de Assad (2008). [34]

Por outro lado, o estudo realizado por Filho (2016), que avalia o Impacto da mudança do clima (temperatura e na precipitação) na produtividade de sementes cultivadas pela Agricultura familiar no Brasil nas regiões Norte e Nordeste, confirma este ponto. $\mathrm{O}$ autor, analisando os cenários downscaled produzidos pelo INPE, indica que a produção da Mandioca (Manihot esculenta), Algodão (Gossypium hirsutum), Café (Coffea arabica), Feijão (Phaseolus vulgaris), Feijão caupi (Vigna unguiculata), Milho (Zea mays), e Abacaxi (Ananas comosus), sofrerão uma redução considerável, colocando em risco a economia e segurança alimentar da população rural no Norte e no Nordeste do Brasil, se políticas públicas direcionadas não forem aplicadas. [35]

As culturas descritas na tabela 1, assim como as indicadas por Filho (2016), conformam os principais produtos que a população indígena costuma semear e consumir. A futura redução das áreas atualmente potenciais para o plantio na região do nordeste, somada à redução da produção das sementes indicadas, gerará um considerável prejuízo e conduzirá muitas famílias indígenas a uma piora de sua situação econômica e alimentar, elevando 


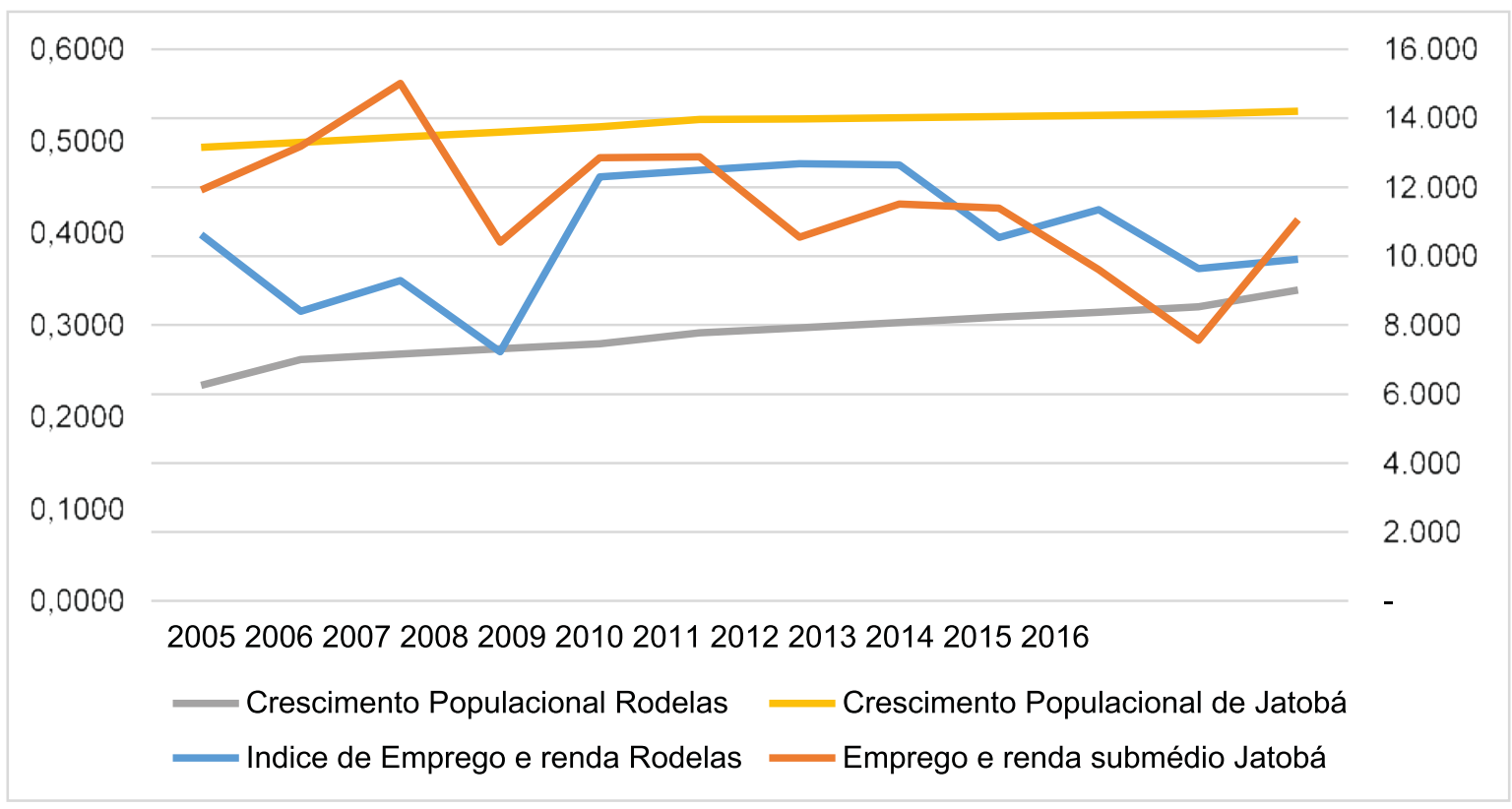

Figura 4. Crescimento populacional, emprego e renda nos municípios Jatobá e Rodelas.

Fonte. Elaboração dos autores com dados do IBGE, FIRJAN e MS (2019).

o número de casos de desnutrição e morte deste grupo no país. ${ }^{16}$

Segundo o último relatório anual da FAO e a OPS (2017) sobre a segurança alimentar, Brasil está entre os principais países susceptíveis a apresentar grandes casos de desnutrição, devido principalmente a seus diferentes biomas e climas extremos. O relatório afirma que os países que mantêm choques climáticos por mais de três anos, têm, em média, mais que o dobro de pessoas subnutridas.[36]

O sistema alimentar está sob pressão dos estressores não climáticos (por exemplo, crescimento da população e da renda, demanda por produtos) e da mudança climática (secas e inundações), impactando os quatro pilares de segurança alimentar, que são disponibilidade, acesso, utilização e estabilidade. [33] Considerando os fatores não climáticos e

16 Segundo dados do MS (2019), 5.653 pessoas morreram neste ano por causas da desnutrição. 501 na região Norte, 2.083 na região Nordeste, 2.219 na região Sudeste, 491 na região Sul e 359 na região Centro- Oeste. Estes dados indicam que aproximadamente 15 pessoas morrem por dia no país por esta razão.[49][50] climáticos dos municípios Jatobá e Rodelas, áreas onde atualmente residem os indígenas Pankararu e Tuxá, observamos que entre o ano 2005 e 2016, a população de ambas regiões vem aumentando. No entanto, desde o ano 2012 sofreram a queda de suas fontes de renda, sendo superadas levemente desde o ano de 2015 (Ver Figura 4). O período de redução coincide com o da estiagem (Ver figura 3), confirmando que, se no futuro as secas forem mais prolongadas e as ocorrências de chuvas mais escassas, muitas pessoas sofrerão a falta de renda e alimentos, assim como a perda de terras aptas para o plantio, comprometendo a sua alimentação e economia. [37]

O povo Pankararu e Tuxá, assim como muitos dos 36 que moram na região do Nordeste, encontram- se assentados nos municípios que futuramente seriam afetados - sujeitos, portanto, a sofrer os impactos das variações climáticas futuras. Segundo dados do MS (2019), neste ano foram registradas 88 mortes de indígenas por desnutrição, situação que poderia piorar ano após ano se não são tomadas provisões 
que diminuam os efeitos das alterações climáticas na região estudada.

A problemática de redução de território para a produção de alimentos se soma a outros fatores como o abandono da agricultura por substituição, o incremento populacional e a falta de terras, elementos que colocam ao indígena numa situação de insegurança alimentar futura. Eventos de seca no passado, nos estados do Nordeste do Brasil, geraram perdas massivas de produção agrícola e pecuária, perda de vidas humanas pela fome, desnutrição e doenças, e deslocamentos de pessoas, bem como impactos sobre as economias regionais e nacionais. [12] Neste sentido, com a finalidade de diminuir a possibilidade de que esta situação se repita, assim como de garantir a vida digna dos diversos povos indígenas que hoje sobrevivem no Submédio São Francisco, todos estes aspectos devem ser analisados em conjunto e, de maneira urgente, formular diversas políticas públicas que garantam o bem estar da população local.

\section{Considerações finais}

Os cenários climáticos nos mostram potenciais reduções na produção de alimentos em diferentes regiões do nordeste brasileiro, especialmente naqueles municípios que se encontram no sertão e na Caatinga brasileira. A narrativas dos povoadores indígenas permitem-nos observar que as variações climáticas de chuvas e temperaturas vem afetando ano após anos sua produção de alimentos e sementes, dificultando a sua antiga e praticada convivência com o semiárido.

Este fato, somado à falta de território dos povos indígenas e ao crescimento populacional, daria passo a uma problemática ainda pior, a qual poderia se agravar ainda mais com o declínio do emprego e renda: dando origem a um processo de empobrecimento e insegurança alimentar na região. Neste sentido, urge aos formuladores de políticas públicas, iniciar ações para diminuir o possível sofrimento da população e o incremento de óbitos por desnutrição na região.

Um dos fatores determinantes de desenvolvimento dos diferentes grupos sociais no Brasil é a disponibilidade de território. O caso dos Tuxá de Rodelas e do povo Pankararu nos mostram que seu desenvolvimento desses povos foi obstado, existindo uma necessidade latente para que esta situação possa ser revertida. Garantir sua estabilidade e sobrevivência compete a todos, no entanto, hoje torna- se uma tarefa difícil devido às poucas ações realizadas e os compromissos assumidos por parte das autoridades e instituições defensoras deste grupo social. Assim, torna-se indispensável tomar medidas como a elaboração de projetos, a tomada de decisões e ações eficazes em defesa dos direitos indígenas.

\section{Agradecimentos}

Os autores agradecem o apoio intelectual e técnico da Sub-rede Desenvolvimento Regional da Rede Brasileira de Pesquisa em Mudanças Climáticas Globais/Rede Clima e do Projeto Observatório das Dinâmicas Socioambientais do Instituto Nacional de Ciência e Tecnologia (INCT-ODISSEIA), coordenados pelo Centro de Desenvolvimento Sustentável/CDS da Universidade de Brasília/UnB. Assim também cabem agradecimentos ao CNPq, FAP-DF e CAPES pelo apoio financeiro.

\section{Bibliografia}

[1] Cbhsf, A Bacia. Principais Características, Minas Gerais: Secretaria do Comitê Belo Horizonte Minas Gerais., 2017.

[2] Painel Brasileiro de Mudanças Climáticas PBMC., Contribuição do Grupo de Trabalho 1 ao Primeiro Relatório de Avaliação Nacional do Painel Brasileiro de Mudanças Climáticas. Sumário Executivo GT1., Rio de Janeiro: PBMC, 2013.

[3] A. M. e. G. J. R. Buainain, “Desenvolvimento rural do semiárido brasileiro: transformações 
recentes, desafios e perspectivas" Confins (Paris), pp. v. 1, p. 1, 2013, https://doi.org/10.4000/ confins.8633.

[4] D. Lindoso E S. Rodrigues Filho, "Vulnerabilidade e adaptação: bases teóricas e conceituais da pesquisa," em O clima em transe: vulnerabilidade e adaptação da agricultura familia, Rio de Janeiro, Garamond, 2016, pp. 19-34.

[5] L. Gaivizzo, "Resilience to climate change in Fundo de Pasto Communities in the semi-arid region of Bahia" Sociedade e natureza, 2019.

[6] J. W. Creswell, Projeto de pesquisa: métodos qualitativo, quantitativo e misto, Porto Alegre: Artmed, 2010, https://doi.org/10.26512/les. v13i1.11610.

[7] K. Charmaz, A construção da teoria fundamentada: guia prático para análise qualitativa., Porto Alegre: Artme, 2009.

[8] C. Teddlie e A. Tashakkori Foundations of Mixed Methods Research: Integrating Quantitative and Qualitative Approaches in the Social and Behavioral Sciences, London: Sage, 2009.

[9] a. d. moura e J. Shukla, "On the Dynamics of Droughts in Northeast Brazil: Observations, Theory and Numerical Experiments with a General Circulation Model" J Atmos, pp. Sci 38: 2653-2675., 1981. https://doi.org/10.1175/15 20-0469(1981)038<2653:otdodi>2.0.co;2

[10] O. De Carvalho, "As secas e os seus Impactos," em A Questao da Agua no Nordeste, Brasilia, CGEE/ANA, 2012, p. 45-100.

[11] D. A. Wilhite, Sivakumar Mvk R. Pulwarty, "Managing drought risk in a changing climate: The role of national drought policy," Weather and Climate Extremes, pp. 3: 4-13., 2014, https:// doi.org/10.1016/j.wace.2014.01.002

[12] J. A. Marengo, R. R. Torres E L. M. AlveS, "Drought in Northeast Brazil-past, present, and future" Theor Appl Climatol, pp. 1-12, 2016, https:// doi.org/10.1007/s00704-016-1840-8.

[13] J. Marengo, A. P. Cunha e L. Alves, "A seca de 2012-15 no semiárido do Nordeste do Brasil no contexto histórico" Climanalise, pp. 04. 49-54, 2016.
[14] J. A. Marengo, L. M. Alves, R. Alvala, A. P. Cunha, S. Brito, O. Moraes, "Climatic characteristics of the 2010-2016 drought in the semiarid Northeast Brazil region" Anais da Academia Brasileira de Ciências, pp. (2 Suppl. 1): 1973-1985, 2018. https://doi. org/10.1590/0001-3765201720170206

[15] T. T. Machado, J. T. Dias E T. C. Silva, "Evolução e avaliação das políticas públicas para a atenuação dos efeitos da seca no semiárido brasileiro" Gaia Scientia, p.v. 11, 2017. https://doi.org/10.22478/ ufpb.1981-1268.2017v11n2.31831

[16] I. B. d. G. e. E. Ibge, "Os indígenas no Censo Demográfico 2010. Primeiras considerações com base no quesito cor ou raça" Documento digital, 2010.

[17] R. Prado, Compreender para Transformar. Tribos Indígenas Nordestinas, Teleiós, 2012.

[18] D. Ribeiro. Sobre o óbvio, Rio de Janeiro: Guanabara, 1986.

[19] E. Silva, "Confundidos com a massa da população: o esbulho das terras indígenas no Nordeste do século XIX" Revista do Arquivo Público Estadual de Pernambuco, pp. 17-29, 1996.

[20] F. Cruz, "Entre índios e sertanejos: o povo indígena Tuxá e a retórica desenvolvimentista chesfiana em Itaparica" Wamon, pp. V. 3, n. 1, 2018.

[21] M. L. Melo, "Os agrestes" SUDENE, 1980.

[22] R. D. B. Salomão, "Etnicidade, territorialidade e ritual entre os Tuxá de Rodelas. Dissertação (Mestrado) em Antropologia Social," Universidade Federal Fluminense, 2006.

[23] J. Oliveira, Somos Índios da Tribo Tuxá Nação Proká Pragaga do Arco e Flecha e Maracá Malacutinga Tuá Deus do Ar, Brasil: Tellus, 2013.

[24] F. Cruz, Quando a terra sair': os índios tuxá de rodelas e a barragem de Itaparica: memórias do desterro, memórias da resistência. Dissertação (Mestrado em Antropologia Social), Brasília: Universidade de Brasília, 2017.

[25] R. Grünewald, "Toré e jurema: emblemas indígenas no nordeste do brasil" Ciência e Cultura , p. vol.60 no.4, 2008. 
[26] J. Arcanjo, Toré e Identidade Étnica: os pipipa da kambixuru (Indios da Serra Negra). Dissertação de mestrado visitada o 16,08,2019, Recife, 2003.

[27] J. Arruti, O reencantamento do mundo: trama historica e Arranjos territoriais Pankaruru. Dissertação (mestrado) Programa de Pos-Graduação em Antropologia Social, Rio de Janeiro: Universidade Federal do Rio de Janeiro, 1996.

[28] M. V. Ferri, "Breves considerações acerca das atuais condições de vida do povo Pankararu" Revista de Estudos e Pesquisas, pp. v.4, n.1, p.109-129, 2007.

[29] A. Zellhuber e R. Siqueira, "Rio São Francisco em descaminho: degradação e revitalização," Caderno CEAS, Salvador - Ba., 2016.

[30] R. Santos e L. Carelli, "Identificação de território indígena: uma reconstituição histórica e geopolítica do povo Tuxá (Rodelas - BA)" em Anais XVII Simpósio Brasileiro de Sensoriamento Remoto - SBSR , João Pessoa-PB, 2014.

[31] Redação, "Povo Pankararu: "A barbárie começou"; tribo indígena tem escola e posto de saúde incendiados," 2018.

[32] Salgueiro, "Incêndio atinge segunda escola indígena Pankararu no Sertão do estado Peritos da Polícia Federal fizeram levantamento no local. Comunidade suspeita de ato criminoso" Salgueiro, 2018.

[33] IPCC , "Special Report on Climate Change, Desertification, Land Degradation, Sustainable Land Management, Food Security, and Greenhouse gas fluxes in Terrestrial Ecosystems Summary for Policymakers Approved Draft," WMO/ UNEP, 2019.

[34] E. Assad e H. S. Pinto, Aquecimento Global e a nova Geografia da Produção agrícola no Brasil. Brasília, Embrapa, 2008.

[35] H. M. Filho, C. Moraes, P. Bennati e R. d. A. Rodrigues, "Mudança do clima e os impactos na agricultura familiar no Norte e Nordeste do Brasil," Centro Internacional de Políticas para o Crescimento Inclusivo (IPC-IG), Brasilia, 2016.
[36] FAO e OPS, "América Latina e o Caribe. PANORAMA DA SEGURANÇA ALIMENTAR E NUTRICIONAL. SISTEMAS ALIMENTARES SUSTENTÁVEIS PARA ACABAR COMA FOME E A MÁ NUTRIÇÃO," FAO e OPS, Santiago, 2017.

[37] Firjan, "Índice FIRJAN de Desenvolvimento Municipal(IFDM)," Brasil, 2019. https://doi. org/10.4000/confins.26246

[38] C. Bermann, "Brasil: um país cheio de energia. Mas qual é o destino de toda essa energia?" Instituto Humanitas Unisinos (IHU), 2009.

[39] A. O. Sevá Filho, Tenotã-Mõ: alertas sobre as consequências dos projetos hidrelétricos no rio Xingu., Berkeley: IRN, 2005.

[40] C. B. Vainer, "O conceito de atingido: uma revisão do debate e diretrizes" IPPUR/UFRJ, 2003.

[41] Comissão Mundial de Barragens CMB, "Barragens e desenvolvimento: um novo modelo para tomadas de decisões," Earthscan Publications, Londres, 2000.

[42] Conselho de Defesa Dos Direitos da Pessoa Humana CDDPH, "Comissão Especial Atingidos por Barragens," CDDPH, Brasília, 2010.

[43] IPEA, Metodologia para o diagnóstico social, econômico e cultural dos atingidos por barragens, Brasília, 2014, p. 49.

[44] G. d. S. Luciano, O índio brasileiro: o que você precisa saber sobre os povos indígenas no Brasil de hoje, Brasília, DF: Ministério da Educação, Secretaria de Educação Continuada, Alfabetização e Diversidade - SECAD em parceria com o Museu Nacional, Laboratório de Pesquisas em Etnicidade, Cultura e Desenvolvimento. 2006. https://doi.org/10.22456/1982- 6524.5174

[45] J. P. Oliveira, "Uma etnologia dos 'índios misturados. Situação colonial, territorialização e fluxos culturais" Estudos de Antropología Social, pp. 47-77, 1998. https://doi.org/10.1590/ s0104- 93131998000100003

[46] Instituto Socioambiental ISA, "Povos Indígenas no Brasil. O povo Pankararu," 2017.

[47] J. Gottmann, The Significance of Territory. Chalottesville, Virginia: University Press of Virginia, 1973. 
[48] J. García, Antropología del Territorio, Madrid: Taller de Ediciones Josefina Betancor, 1976.

[49] Folha de S.Paulo, "Em média, 15 pessoas morrem de desnutrição por dia no Brasil," Folha de S.Paulo, S.Paulo, 2019.

[50] Ministério De Saúde, "Óbitos p/Ocorrênc segundo Município Grupo CID-10: Desnutrição," 2017.

\section{(c) $\underset{\mathrm{BY}}{\mathrm{NC}} \mathrm{\Theta}$}

